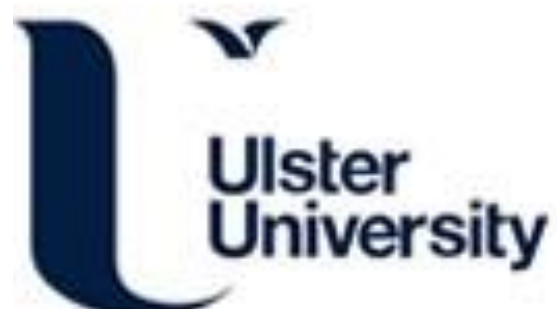

Nut and legume consumption and human health: an umbrella review of observational studies

Martini, D., Godos, J., Marventano, S., Tieri, M., Ghelfi, F., Titta, L., Lafranconi, A., Trigueiro, H., Gambera, A., Alonzo, E., Sciacca, S., Buscemi, S., Ray, S., Galvano, F., Del Rio, D., \& Grosso, G. (2021). Nut and legume consumption and human health: an umbrella review of observational studies. International Journal of Food Sciences and Nutrition, 72(7), 871-878. https://doi.org/10.1080/09637486.2021.1880554

Link to publication record in Ulster University Research Portal

\section{Published in:}

International Journal of Food Sciences and Nutrition

Publication Status:

Published (in print/issue): 03/10/2021

DOI:

10.1080/09637486.2021.1880554

\section{Document Version}

Author Accepted version

\section{General rights}

Copyright for the publications made accessible via Ulster University's Research Portal is retained by the author(s) and / or other copyright owners and it is a condition of accessing these publications that users recognise and abide by the legal requirements associated with these rights.

\section{Take down policy}

The Research Portal is Ulster University's institutional repository that provides access to Ulster's research outputs. Every effort has been made to ensure that content in the Research Portal does not infringe any person's rights, or applicable UK laws. If you discover content in the Research Portal that you believe breaches copyright or violates any law, please contact pure-support@ulster.ac.uk. 


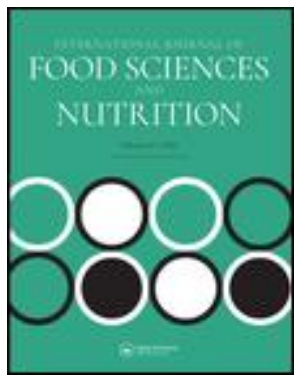

\section{Nut and legume consumption and human health: an umbrella review of observational studies}

\begin{tabular}{|c|c|}
\hline Journal: & International Journal of Food Sciences and Nutrition \\
\hline Manuscript ID & CIJF-2021-0053 \\
\hline Manuscript Type: & Research Article \\
\hline $\begin{array}{r}\text { Date Submitted by the } \\
\text { Author: }\end{array}$ & 13-Jan-2021 \\
\hline Complete List of Authors: & $\begin{array}{l}\text { Martini, Daniela; Universita degli Studi di Milano, Food, Environmental, } \\
\text { and Nutritional Sciences } \\
\text { Grosso, Giuseppe; University of Catania, Department of Biomedical and } \\
\text { Biotechnological Sciences } \\
\text { Godos, Justyna; University of Catania, Biomedical and Biotechnological } \\
\text { Sciences } \\
\text { Marventano, Stefano; Azienda Unita Sanitaria Locale della Romagna, } \\
\text { Rimini Women's Health, Childhood and Adolescent } \\
\text { Tieri, Maria; European Institute of Oncology IRCCS, Department of } \\
\text { Experimental Oncology } \\
\text { Ghelfi, Francesca; IRCCS Ca' Granda Ospedale Maggiore Policlinico, } \\
\text { Fondazione De Marchi-Department of Pediatrics } \\
\text { Titta, Lucilla; European Institute of Oncology IRCCS, Department of } \\
\text { Experimental Oncology } \\
\text { Lafranconi, Alessandra; Maastricht University, Care and Public Health } \\
\text { Research Institute } \\
\text { Trigueiro, Helena; St John's Innovation Centre, NNEdPro Global Centre } \\
\text { for Nutrition and Health } \\
\text { Gambera, Angelo; Azienda Ospedaliero-Universitaria Policlinico-Vittorio } \\
\text { Emanuele, Policlinico-Vittorio Emanuele } \\
\text { Alonzo, Elena; ASP Catania, Food Public Health Service } \\
\text { Sciacca, Salvatore; Azienda Ospedaliero-Universitaria Policlinico-Vittorio } \\
\text { Emanuele, Cancer Registry } \\
\text { Buscemi, Silvio; University of Palermo, DIBIMIS } \\
\text { Ray, Sumantra; St John's Innovation Centre, NNEdPro Global Centre for } \\
\text { Nutrition and Health } \\
\text { Galvano, Fabio; University od Catania, Biomedical and Biotechnological } \\
\text { Sciences } \\
\text { Del Rio, Daniele; University of Parma, , Department of Veterinary } \\
\text { Science }\end{array}$ \\
\hline Keywords: & $\begin{array}{l}\text { nut, legume, meta-analysis, umbrella review, evidence, cancer, coronary } \\
\text { heart diseases, Cardiovascular diseases, Cardiovascular disease, } \\
\text { Coronary heart disease }\end{array}$ \\
\hline
\end{tabular}


1

2

3

4

5

6

7

8

9

10

11

12

13

14

15

16

17

18

19

20

21

22

23

24

25

26

27

28

29

30

31

32

33

34

35

36

37

38

39

40

41

42

43

44

45

46

47

48

49

50

51

52

53

54

55

56

57

58

59

60

\section{SCHOLARONE ${ }^{\text {m }}$ \\ Manuscripts}




\title{
Nut and legume consumption and human health: an umbrella review of observational studies
}

\author{
Daniela Martini ${ }^{1}$, Justyna Godos ${ }^{2}$, Stefano Marventano ${ }^{3}$, Maria Tieri $^{4}$, Francesca Ghelfi $^{5,6}$, \\ Lucilla Titta ${ }^{4}$, Alessandra Lafranconi $^{7,8}$, Helena Trigueiro ${ }^{6}$, Angelo Gambera $^{9}$, Elena \\ Alonzo $^{10}$, Salvatore Sciacca ${ }^{11}$, Silvio Buscemi ${ }^{12}$, Sumantra Ray 6 13,14,15, Fabio Galvano ${ }^{2}$, \\ Daniele Del Rio $6,16,17$, Giuseppe Grosso ${ }^{2,6}$
}

${ }^{1}$ Department of Food, Environmental, and Nutritional Sciences, Università degli Studi di Milano, Milan, Italy;

${ }^{2}$ Department of Biomedical and Biotechnological Sciences, University of Catania, Catania, Italy;

${ }^{3}$ Rimini Women's Health, Childhood and Adolescent Department, AUSL Romagna, Rimini, Italy;

${ }^{4}$ SmartFood Program, Department of Experimental Oncology, IEO, European Institute of Oncology IRCCS, Milan, Italy;

${ }^{5}$ Fondazione De Marchi-Department of Pediatrics, IRCCS Ca' Granda Ospedale Maggiore Policlinico, Milan, Italy;

${ }^{6}$ NNEdPro Global Centre for Nutrition and Health, St John's Innovation Centre, Cambridge, United Kingdom;

${ }^{7}$ University of Milano - Bicocca, Milan, Italy;

${ }^{8}$ Care and Public Health Research Institute, Maastricht University, Maastricht, The Netherlands;

${ }^{9}$ Azienda Ospedaliero-Universitaria Policlinico-Vittorio Emanuele, Catania, Italy;

${ }^{10}$ Food and Nutrition Security and Public Health Service, ASP Catania, Catania, Italy; 
${ }^{11}$ Integrated Cancer Registry of Catania-Messina-Siracusa-Enna, Azienda OspedalieroUniversitaria Policlinico-Vittorio Emanuele, Catania, Italy;

${ }^{12}$ Biomedical Department of Internal and Specialist Medicine (DIBIMIS), University of Palermo, Palermo, Italy;

${ }^{13}$ Wolfson College at the University of Cambridge, United Kingdom,

${ }^{14}$ Nutrition Innovation Centre for Food and Health at Ulster University, United Kingdom;

${ }^{15}$ Medical Research Council (MRC) Human Nutrition Research Unit, Cambridge, United Kingdom;

${ }^{16}$ Human Nutrition Unit, Department of Veterinary Science, University of Parma, Parma, Italy;

${ }^{17}$ School of Advanced Studies on Food and Nutrition, University of Parma, Parma, Italy.

Corresponding author: Giuseppe Grosso, Department of Biomedical and Biotechnological Sciences, University of Catania, Via Santa Sofia 97, 95123 Catania, Italy (email: giuseppe.grosso@unict.it; Phone/Fax+39 0954781187). 


\title{
Nut and legume consumption and human health: an umbrella review of observational studies
}

\begin{abstract}
Keywords: nut; legume; meta-analysis; umbrella review; evidence; non-communicable diseases; cardiovascular disease; cancer; coronary heart disease; stroke; colon cancer
\end{abstract}

\begin{abstract}
Consumption of nuts and legumes has been associated with several health benefits. The aim of this study was to systematically review existing meta-analyses of observational studies on nut and legume consumption and various health outcomes. The level of evidence for their association on health was assessed. Out of the 21 meta-analyses, a possible association with decreased risk of colorectal adenoma and coronary heart disease was assessed for higher legume consumption, and a decreased risk of cardiovascular and cancer mortality, colon cancer, hypertension and ischaemic stroke for higher nut consumption; the association between legume consumption and CVD, as well as nut consumption and risk of cancer, cardiovascular diseases incidence, and mortality from all causes was deemed as "limited" due to heterogeneity between results and/or potential confounding factors. General benefit toward better health can be observed for both nut and legume consumption; further studies are needed to better elucidate potential confounding factors.
\end{abstract}




\section{Introduction}

The scientific community agrees that a dietary pattern rich in plant-derived foods might exert beneficial effects on human health (Angelino et al. 2019). The global burden of disease has been shown to be strongly affected by nutritional risk factors and addressing malnutrition would impact global mortality and years of life lived with disability (GBD 2017 Diet Collaborators 2019; GBD 2019 Risk Factors Collaborators 2020). Traditional healthy dietary patterns have gained large interest due to their content in fruit and vegetables, but also in legumes and nuts: considered key features for a balanced healthy diet, these food groups are globally accessible and easily embeddable in any sort of diet worldwide (Mocciaro et al. 2018). Several overviews of the scientific literature emphasized on the potential benefits of nut and legume consumption, especially toward age-related diseases (Bouchenak \& LamriSenhadji 2013; Grosso \& Estruch 2016). Nuts and legumes, among other foods, characterize the pillars of traditional Mediterranean dietary pattern, which has been associated with a number of health benefits (Grosso et al. 2017) being characterized by a high consumption of plant-based foods (i.e. wholegrain, fruit and vegetables, legumes, nuts) moderate amounts of animal-foods, and extra-virgin olive oil as dressing and main source of monounsaturated fatty acids (MUFA). Among the plant-based foods characterizing the Mediterranean diet, nuts and legumes play an important role due to their favourable nutrient profile.

The term "nuts" include a wide range of different products such as chestnut, brazil nut, and hazelnut, that are true nuts also from a botanical point of view, but also almond, cashew, and peanut, and other seeds, which are energy and nutrient dense foods characterized by high content of protein, fats, vitamins, minerals. Legumes, also known as pulses, also comprehend a wide list of products such as peas, beans, chickpeas and many others, generally high in protein, low in fats (except for soy), and good sources of fibre and some micronutrients. 
Moreover, both nuts and legumes are good sources of phytochemicals like polyphenols that are often investigated for explaining part of the preventive role associated with the consumption of these two food groups (Godos et al. 2017; Marino et al. 2020).

With a various extent, the content in fiber, phytochemicals, and optimal fatty acid profile of nuts and legumes provide indeed an ideal mix of nutrients and antioxidants potentially leading their role in decreasing non-communicable diseases (Martini 2019; Dinu et al. 2020).

Previous studies discussed the potential for a decreased risk of cardiovascular disease (CVD) and certain cancers associated with consumption of nuts and legumes, but a comprehensive assessment of the level of evidence is lacking. Thus, the aim of the present umbrella review was to systematically review existing meta-analyses on nut and legume consumption and all available outcomes and to evaluate the level of evidence for their impact on disease risk.

\section{Methods}

\section{Study selection}

We performed a systematic review of existing meta-analyses of prospective cohort studies on nut and legume consumption and various health outcomes in Medline and Embase electronic databases until January 2017. The search strategy included: [(pulse OR pulses OR bean OR beans OR lentil OR lentils OR legume OR legumes OR pea OR peas OR chickpea OR chickpeas tree nuts OR tree nut OR nuts OR nut OR almond OR almonds OR pecan OR pecans OR brazil nuts OR hazelnut OR hazelnuts OR macadamia OR pine nuts OR pistachio OR pistachios OR walnut OR walnuts OR peanut OR peanuts OR cashew OR cashews) AND (meta-analysis OR meta-analyzed OR pooled analysis)]. Only meta-analyses of prospective cohort studies on legume or nut consumption as the variable of exposure were included for evaluation. Studies on soy or isoflavones were not included. Meta-analyses of RCTs with 


\section{Data extraction}

From each meta-analysis included, the following information was extracted: name of the first author and year of publication, outcome, number of studies included in the meta-analysis, study design of included studies (i.e., case-control/cross-sectional and prospective), total number of population, number of cases, type of exposure, measure of exposure [including highest versus lowest (reference) category of exposure or dose-response incremental servings per day (linear)], effect sizes [risk ratio (RR), odds ratio (OR), or hazard ratio (HR)].

\section{Data evaluation and evidence synthesis}

Where more than one meta-analysis was conducted on the same outcome, including the same study design, and the same population group, the concordance for the main outcome of interest, including direction and magnitude (overlapping confidence interval) of the association was evaluated. For further analyses, the most recent/exhaustive study was considered. The pooled analyses of the highest versus. the lowest (reference) category of exposure and dose-response analyses were evaluated. Direction and magnitude of the association, heterogeneity (I2) of results, and subgroup/stratified analyses for potential confounding factors were considered to have indication of level of evidence. Criteria used for evidence categorization were modified from the Joint WHO/FAO Expert Consultation (Degrees of evidence by the Joint WHO/FAO Expert Consultation. 


\section{http://www.who.int/nutrition/topics/5 population nutrient/en/\#diet 5.1.2 Accessed}

November 2015) (Table 1). Briefly, the relation between exposure and outcomes was categorized as following: suggestive/limited/contrasting evidence, when there was availability of solely meta-analyses of case-control studies, limited prospective cohort studies included in meta-analyses $(\mathrm{n}<3$ ), or evident contrasting results from meta-analyses with the same level of evidence; possible evidence, when there was availability of meta-analyses with lack of information on/significant heterogeneity (I2 $>50 \%$ ) or identification of potential confounding factors (i.e., different findings in subgroups); probable association, when there was availability of meta-analyses of prospective cohort studies with no heterogeneity, no potential confounding factors identified, and eventual disagreement of results over time reasonably explained (and evidence of dose-response relation further investigated); convincing association, when there was concordance between meta-analyses of RCTs and observational studies. Lack of fulfillment of the previous criteria was considered as insufficient evidence.

\section{Results}

Study selection

Of 139 articles identified through the database search, 54 were excluded based on title and 29 after abstract evaluation (Figure 1). Twenty-one studies were further excluded because metaanalyses of RCT $(n=11)$, narrative/systematic reviews without quantitative evaluation of the association between exposure and outcome $(n=2)$, pooled analysis of prospective cohort studies $(n=1)$, investigating biomarkers $(n=2)$, having different exposure (i.e., soy, soy isoflavones; $\mathrm{n}=5$ ). Thus, a total number of 6 studies on legume consumption (Wang et al. 2013; Afshin et al. 2014; Shi et al. 2014; Zhu et al. 2015; Marventano et al. 2017; Zhong et al. 2018) and 15 on nut consumption (Afshin et al. 2014; Luo et al. 2014; Zhou et al. 2014; 


\section{Characteristics of the studies on legume consumption and health outcomes}

The main characteristics of the studies exploring the risk associated to high vs. low legume consumption for 5 unique outcomes from 3 non-overlapping meta-analyses and the risk associated to linear legume consumption for 4 unique outcomes from 1 non-overlapping meta-analysis are shown in Figure 2 and Supplementary Table 1, respectively. A decreased risk of CVD, CHD, and colorectal adenoma was observed for higher vs. lower intake of legume (Figure 2). One meta-analysis (Zhong et al. 2018) on a limited number of prospective cohort studies $(<3)$ and case-control studies also reported a potential inverse association between high legume intake and endometrial cancer risk. Limited information on potential confounding factors showed that results on colorectal cancer risk were significant only when considering Asian cohorts (Marventano et al. 2017).

\section{Characteristics of the studies on nut consumption and health outcomes}

An overview of the main characteristics of the studies included and the risk estimates of various health outcomes for the highest versus the lowest category of nut consumption are reported for 15 unique outcomes extracted from 9 non-overlapping meta-analyses in Figure 3 and the risk estimates of 10 outcomes from 5 non-overlapping meta-analyses for linear consumption of nuts are reported in Supplementary Table 2. A significant inverse association between nut consumption and CVD risk (including subtypes CHD and stroke) and mortality, as well as all-cause mortality and total and colorectal cancer was found: however, the meta- 
analysis on risk of CVD reported significant heterogeneity and a study specifically exploring myocardial infarction reported null results (Figure 3). The results on CVD mortality and cancer risk were in line with those estimated for increasing consumption (linear) of nuts (Supplementary Table 2). Two non-overlapping meta-analyses conducted on a limited number of prospective cohort studies $(<3)$ or case-control studies reported null results on individual types of cancers (Wu et al. 2015) and stoke (hemorrhagic) (Zhang et al. 2015). When controlling for potential confounding factors, results were only relatively consistent, since significance in studies on CVD outcomes varied by geographical region (i.e., a decreased risk for higher nut consumption was stably observed in US cohorts but not consistently in European ones), as well as results on stroke (total) were significant only in women while those on cancer (any) and CVD risk only in men. When controlling for stability of findings over time, a previous study on cancer risk reported non-significant results (Wu et al. 2015).

\section{Summary of evidence}

The strength of the evidence was evaluated through checking for the pre-selected criteria as reported in Supplementary Table 3. A possible association with decreased risk of colorectal adenoma and CHD was assessed for higher legume consumption, and a decreased risk of CVD and cancer mortality, colon cancer, hypertension and ischemic stroke for higher nut consumption; the association between legume consumption and CVD, as well as nut consumption and risk of cancer, CVD, CHD (fatal), stroke, and mortality from all causes was deemed as limited mostly due to heterogeneity between results and/or potential residual confounding. No probable nor convincing associations were found. Limited or insufficient evidence has been reported for all other outcomes investigated (Table 1). 


\section{Discussion}

The findings of this umbrella review emphasize on the convincing role of nut and legume consumption in affecting cardiovascular and, probably, on general cancer risk. Despite with great differences between nut and legume types, these foods are rich in nutrients, such as protein, unsaturated fatty acids, fiber, vitamins, minerals, as well as a number of phytochemicals, including polyphenols and phytosterols (Ros 2010). Several mechanisms have been hypothesized to explain the reduced CVD risk associated with nut consumption. The protein content of nuts accounts for about $10-25 \%$ and includes aminoacids, such as Larginine, which is involved in the production of nitric oxide (NO) and an endogenous vasodilator that may play a role in regulating blood pressure (Brufau et al. 2006). The fat content includes monounsaturated fatty acids (MUFA), such as oleic acid in most of nuts, and polyunsaturated fatty acids (PUFA), such as alpha-linolenic acid in pine nuts and walnuts; MUFA and PUFA are able to reduce serum concentrations of the vasoconstrictor thromboxane 2, which might influence blood pressure regulation. Together with polyphenols and group B vitamins and folate, nuts may prevent oxidative stress by scavenging or neutralizing reactive oxidant species and improve inflammatory status by reducing circulating levels of soluble cellular adhesion molecules, such as intercellular adhesion molecule-1 (ICAM-1), vascular cell adhesion molecule-1 (VCAM-1), and E-selectin, which are released from the activated endothelium and circulating monocytes (Segura et al. 2006). Moreover, content in fiber and polyphenols of nuts and legumes may play a role in modulating the profile of gut microbiome exerting favourable effects toward systemic inflammation (Salvucci 2019; Mena \& Bresciani 2020). Finally, the presence of mineral such as magnesium, potassium, and calcium, may play a role on blood pressure through the production NO, prostacyclin and calcium channel blockade, the reduction of the extracellular 
fluid volume modulating the activity of the renin-angiotensin system, and the inhibition of the parathyroid hormone that induces hypertension (Casas-Agustench et al. 2011).

From a clinical point of view, nut consumption has been revealed to be effective in reducing cardiovascular risk factors. A pooled analysis of RCTs showed a potential role of nuts in reducing blood lipids: a diet supplemented with a daily consumption of $67 \mathrm{~g}$ of nuts reduced total cholesterol (TC), low-density lipoprotein-cholesterol (LDL-C), ratio of LDL-C to HDLC, and ratio of TC to HDL-C concentration (Sabaté et al. 2010). Similar findings have been reported also for specific types of nuts: for instance, a meta-analysis on diets supplemented with walnuts led to reduction of TC and LDL-C (Guasch-Ferré et al. 2018); another metaanalysis on diets supplemented with almonds showed reduction of TC and a non-significant trend in LDL-C reduction (Del Gobbo et al. 2015); no general effects on high-density lipoprotein-cholesterol (HDL-C) and triglycerides concentrations have been reported. Also a meta-analysis on RCT investigating the effects of legumes on blood lipids showed that diets including legumes led to reduction in TC and LDL-C (Bazzano et al. 2011). Regarding blood pressure, a meta-analysis of RCTs showed that diets supplemented with nuts reduced SBP and DBP, despite the effect was relevant only in individuals without T2DM (Mohammadifard et al. 2015). Similarly, results from another meta-analysis of RCTs showed that dietary pulses, exchanged isocalorically for other foods, significantly lowered SBP and DBP (Jayalath et al. 2014). Contrasting results have been found regarding glycemic control: despite no evidence from observational studies has been concluded, a meta-analysis of RCTs on the effects of nut consumption in diabetic individuals showed an improvement in glycemic control, including lowering $\mathrm{HbAlc}$ and fasting glucose but not fasting insulin and homeostatic model assessment (Viguiliouk et al. 2014). Similarly, also a meta-analysis of RCTs on legumes showed lowering of fasting blood glucose and insulin, despite most of 
results were stronger when considering legume consumption in the context of low-glycaemic index or high-fiber diets (Sievenpiper et al. 2009).

Nuts and legumes have been proposed as foods potentially playing a role as anticancer agents. Their components may synergistically exert antioxidative and anti-inflammatory properties that may contribute to the prevention of processes leading to tumor initiation, invasion, and intravasation into blood and lymphatics vessels, a process further enhanced by the inflammatory status, such as vascular permeability induced by tumor necrosis factor and prostaglandin production (Falasca et al. 2014). Certain polyphenols contained in plantderived foods, including nuts and legumes, have been shown to affect various cellular processes involved in cancer development and progression, including cell survival, cell proliferation, cell invasion, and angiogenesis (Falasca \& Casari 2012). With special regard to colon cancer, nuts and legumes are also a dietary source of fiber, well-known to play a role in lower gastrointestinal cancer prevention (González \& Salas-Salvadó 2006). Finally, nuts and legumes may indirectly exert anticancer activity through their ability to alter lipid profiles and cell metabolism (Grosso et al. 2013; Tárraga López et al. 2014).

The present study should be considered in light of some limitations. The results pooled from different cohort studies may have different methods for dietary exposure estimation and lack of general identification of type of nuts or legumes, which might play a role for the different effect on health. Moreover, it has been pointed out that plant-food consumption is a healthconscious choice (Grosso et al. 2015), thus confounding from background variables potentially leading to effect modification should be taken into account. 
In conclusions, given the validity of the presented findings from observational studies and the agreement of results with clinical trials, we can conclude that a diet containing nuts and legumes reduces the risk of CVD. Despite convincing evidence of an association has been observed also for cancer outcomes, further studies in clinical settings are needed to better understand the potential mechanisms underlying the aforementioned relation.

\section{Acknowledgments}

No funding.

\section{Declaration of interests}

The authors declare no conflicts of interest. 


\section{References}

Afshin A, Micha R, Khatibzadeh S, Mozaffarian D. 2014. Consumption of nuts and legumes and risk of incident ischemic heart disease, stroke, and diabetes: a systematic review and meta-analysis. Am J Clin Nutr. 100:278-288.

Angelino D, Godos J, Ghelfi F, Tieri M, Titta L, Lafranconi A, Marventano S, Alonzo E, Gambera A, Sciacca S, et al. 2019. Fruit and vegetable consumption and health outcomes: an umbrella review of observational studies. Int J Food Sci Nutr. 70:652-667.

Aune D, Keum N, Giovannucci E, Fadnes LT, Boffetta P, Greenwood DC, Tonstad S, Vatten LJ, Riboli E, Norat T. 2016. Nut consumption and risk of cardiovascular disease, total cancer, all-cause and cause-specific mortality: a systematic review and dose-response meta-analysis of prospective studies. BMC Med. 14:207.

Bazzano LA, Thompson AM, Tees MT, Nguyen CH, Winham DM. 2011. Non-soy legume consumption lowers cholesterol levels: a meta-analysis of randomized controlled trials. Nutr Metab Cardiovasc Dis. 21:94-103.

Bouchenak M, Lamri-Senhadji M. 2013. Nutritional quality of legumes, and their role in cardiometabolic risk prevention: a review. J Med Food. 16:185-198.

van den Brandt PA, Schouten LJ. 2015. Relationship of tree nut, peanut and peanut butter intake with total and cause-specific mortality: a cohort study and meta-analysis. Int $\mathrm{J}$ Epidemiol. 44:1038-1049.

Brufau G, Boatella J, Rafecas M. 2006. Nuts: source of energy and macronutrients. Br J Nutr. 96 Suppl 2:S24-8.

Casas-Agustench P, López-Uriarte P, Ros E, Bulló M, Salas-Salvadó J. 2011. Nuts, hypertension and endothelial function. Nutr Metab Cardiovasc Dis. 21 Suppl 1:S21-33. 
Del Gobbo LC, Falk MC, Feldman R, Lewis K, Mozaffarian D. 2015. Effects of tree nuts on blood lipids, apolipoproteins, and blood pressure: systematic review, meta-analysis, and doseresponse of 61 controlled intervention trials. Am J Clin Nutr. 102:1347-1356.

Dinu M, Pagliai G, Angelino D, Rosi A, Dall'Asta M, Bresciani L, Ferraris C, Guglielmetti M, Godos J, Del Bo’ C, et al. 2020. Effects of Popular Diets on Anthropometric and Cardiometabolic Parameters: An Umbrella Review of Meta-Analyses of Randomized Controlled Trials. Adv Nutr. 11:815-833.

Falasca M, Casari I. 2012. Cancer chemoprevention by nuts: evidence and promises. Front Biosci (Schol Ed). 4:109-120.

Falasca M, Casari I, Maffucci T. 2014. Cancer chemoprevention with nuts. J Natl Cancer Inst. 106.

GBD 2017 Diet Collaborators. 2019. Health effects of dietary risks in 195 countries, 19902017: a systematic analysis for the Global Burden of Disease Study 2017. Lancet. 393:19581972.

GBD 2019 Risk Factors Collaborators. 2020. Global burden of 87 risk factors in 204 countries and territories, 1990-2019: a systematic analysis for the Global Burden of Disease Study 2019. Lancet. 396:1223-1249.

Godos J, Rapisarda G, Marventano S, Galvano F, Mistretta A, Grosso G. 2017. Association between polyphenol intake and adherence to the Mediterranean diet in Sicily, southern Italy. NFS Journal. 8:1-7.

González CA, Salas-Salvadó J. 2006. The potential of nuts in the prevention of cancer. Br J Nutr. 96 Suppl 2:S87-94.

Grosso G, Buscemi S, Galvano F, Mistretta A, Marventano S, La Vela V, Drago F, Gangi S, Basile F, Biondi A. 2013. Mediterranean diet and cancer: epidemiological evidence and 
mechanism of selected aspects. BMC Surg. 13 Suppl 2:S14.

Grosso G, Estruch R. 2016. Nut consumption and age-related disease. Maturitas. 84:11-16.

Grosso G, Marventano S, Yang J, Micek A, Pajak A, Scalfi L, Galvano F, Kales SN. 2017. A comprehensive meta-analysis on evidence of Mediterranean diet and cardiovascular disease: Are individual components equal? Crit Rev Food Sci Nutr. 57:3218-3232.

Grosso G, Yang J, Marventano S, Micek A, Galvano F, Kales SN. 2015. Nut consumption on all-cause, cardiovascular, and cancer mortality risk: a systematic review and meta-analysis of epidemiologic studies. Am J Clin Nutr. 101:783-793.

Guasch-Ferré M, Li J, Hu FB, Salas-Salvadó J, Tobias DK. 2018. Effects of walnut consumption on blood lipids and other cardiovascular risk factors: an updated meta-analysis and systematic review of controlled trials. Am J Clin Nutr. 108:174-187.

Guo K, Zhou Z, Jiang Y, Li W, Li Y. 2015. Meta-analysis of prospective studies on the effects of nut consumption on hypertension and type 2 diabetes mellitus. J Diabetes. 7:202212.

Jayalath VH, de Souza RJ, Sievenpiper JL, Ha V, Chiavaroli L, Mirrahimi A, Di Buono M, Bernstein AM, Leiter LA, Kris-Etherton PM, et al. 2014. Effect of dietary pulses on blood pressure: a systematic review and meta-analysis of controlled feeding trials. Am J Hypertens. 27:56-64.

Luo C, Zhang Y, Ding Y, Shan Z, Chen S, Yu M, Hu FB, Liu L. 2014. Nut consumption and risk of type 2 diabetes, cardiovascular disease, and all-cause mortality: a systematic review and meta-analysis. Am J Clin Nutr. 100:256-269.

Ma L, Wang F, Guo W, Yang H, Liu Y, Zhang W. 2014. Nut consumption and the risk of coronary artery disease: a dose-response meta-analysis of 13 prospective studies. Thromb Res. 134:790-794. 
Marino M, Del Bo’ C, Martini D, Porrini M, Riso P. 2020. A review of registered clinical trials on dietary (poly)phenols: past efforts and possible future directions. Foods. 9.

Martini D. 2019. Health benefits of mediterranean diet. Nutrients. 11.

Marventano S, Izquierdo Pulido M, Sánchez-González C, Godos J, Speciani A, Galvano F, Grosso G. 2017. Legume consumption and CVD risk: a systematic review and meta-analysis. Public Health Nutr. 20:245-254.

Mayhew AJ, de Souza RJ, Meyre D, Anand SS, Mente A. 2016. A systematic review and meta-analysis of nut consumption and incident risk of CVD and all-cause mortality. Br J Nutr. 115:212-225.

Mena P, Bresciani L. 2020. Dietary fibre modifies gut microbiota: what's the role of (poly)phenols? Int J Food Sci Nutr. 71:783-784.

Mocciaro G, Ziauddeen N, Godos J, Marranzano M, Chan M-Y, Ray S. 2018. Does a Mediterranean-type dietary pattern exert a cardio-protective effect outside the Mediterranean region? A review of current evidence. Int J Food Sci Nutr. 69:524-535.

Mohammadifard N, Salehi-Abargouei A, Salas-Salvadó J, Guasch-Ferré M, Humphries K, Sarrafzadegan N. 2015. The effect of tree nut, peanut, and soy nut consumption on blood pressure: a systematic review and meta-analysis of randomized controlled clinical trials. Am J Clin Nutr. 101:966-982.

Ros E. 2010. Health benefits of nut consumption. Nutrients. 2:652-682.

Sabaté J, Oda K, Ros E. 2010. Nut consumption and blood lipid levels: a pooled analysis of 25 intervention trials. Arch Intern Med. 170:821-827.

Salvucci E. 2019. The human-microbiome superorganism and its modulation to restore health. Int J Food Sci Nutr. 70:781-795. 
Segura R, Javierre C, Lizarraga MA, Ros E. 2006. Other relevant components of nuts: phytosterols, folate and minerals. Br J Nutr. 96 Suppl 2:S36-44.

Shao C, Tang H, Zhao W, He J. 2016. Nut intake and stroke risk: A dose-response metaanalysis of prospective cohort studies. Sci Rep. 6:30394.

Shi ZQ, Tang JJ, Wu H, Xie CY, He ZZ. 2014. Consumption of nuts and legumes and risk of stroke: a meta-analysis of prospective cohort studies. Nutr Metab Cardiovasc Dis. 24:12621271.

Sievenpiper JL, Kendall CWC, Esfahani A, Wong JMW, Carleton AJ, Jiang HY, Bazinet RP, Vidgen E, Jenkins DJA. 2009. Effect of non-oil-seed pulses on glycaemic control: a systematic review and meta-analysis of randomised controlled experimental trials in people with and without diabetes. Diabetologia. 52:1479-1495.

Tárraga López PJ, Albero JS, Rodríguez-Montes JA. 2014. Primary and secondary prevention of colorectal cancer. Clin Med Insights Gastroenterol. 7:33-46.

Viguiliouk E, Kendall CWC, Blanco Mejia S, Cozma AI, Ha V, Mirrahimi A, Jayalath VH, Augustin LSA, Chiavaroli L, Leiter LA, et al. 2014. Effect of tree nuts on glycemic control in diabetes: a systematic review and meta-analysis of randomized controlled dietary trials. PLoS ONE. 9:e103376.

Wang Y, Wang Z, Fu L, Chen Y, Fang J. 2013. Legume consumption and colorectal adenoma risk: a meta-analysis of observational studies. PLoS ONE. 8:e67335.

Weng Y-Q, Yao J, Guo M-L, Qin Q-J, Li P. 2016. Association between nut consumption and coronary heart disease: a meta-analysis. Coron Artery Dis. 27:227-232.

Wu J, Zeng R, Huang J, Li X, Zhang J, Ho JC-M, Zheng Y. 2016. Dietary Protein Sources and Incidence of Breast Cancer: A Dose-Response Meta-Analysis of Prospective Studies. Nutrients. 8. 
Wu L, Wang Z, Zhu J, Murad AL, Prokop LJ, Murad MH. 2015. Nut consumption and risk of cancer and type 2 diabetes: a systematic review and meta-analysis. Nutr Rev. 73:409-425. Zhang Z, Xu G, Wei Y, Zhu W, Liu X. 2015. Nut consumption and risk of stroke. Eur J Epidemiol. 30:189-196.

Zhong X-S, Ge J, Chen S-W, Xiong Y-Q, Ma S-J, Chen Q. 2018. Association between Dietary Isoflavones in Soy and Legumes and Endometrial Cancer: A Systematic Review and Meta-Analysis. J Acad Nutr Diet. 118:637-651.

Zhou D, Yu H, He F, Reilly KH, Zhang J, Li S, Zhang T, Wang B, Ding Y, Xi B. 2014. Nut consumption in relation to cardiovascular disease risk and type 2 diabetes: a systematic review and meta-analysis of prospective studies. Am J Clin Nutr. 100:270-277.

Zhu B, Sun Y, Qi L, Zhong R, Miao X. 2015. Dietary legume consumption reduces risk of colorectal cancer: evidence from a meta-analysis of cohort studies. Sci Rep. 5:8797. 


\section{Figure legend}

Figure 1. Flow chart of study selection.

Figure 2. Summary results from meta-analyses of prospective cohort studies on legume consumption on various health outcomes included in umbrella review.

Figure 3. Summary results from meta-analyses of prospective cohort studies on nut consumption on various health outcomes included in umbrella review.

\section{Table legend}

Table 1. Level of evidence for the association between nut and legume consumption and health outcomes.

\section{Supplementary material legend}

Supplementary Table 1. Summary results from meta-analyses investigating continuous linear exposure to legume consumption and health outcomes.

Supplementary Table 2. Summary results from meta-analyses investigating continuous linear exposure to nut consumption and health outcomes.

Supplementary Table 3. Variables investigated to address the strength of evidence from selected meta-analyses on legume and nut consumption and health outcomes. 
Table 1. Level of evidence for the association between nut and legume consumption and health outcomes.

\begin{tabular}{|c|c|c|c|}
\hline $\begin{array}{l}\text { Level of } \\
\text { evidence* }\end{array}$ & Criterias & $\begin{array}{l}\text { Legume } \\
\text { consumption }\end{array}$ & Nut consumption \\
\hline $\begin{array}{l}\text { Convincin } \\
g\end{array}$ & $\begin{array}{l}\text { Meta-analyses of } \\
\text { prospective cohort } \\
\text { studies with evidence } \\
\text { of dose-response } \\
\text { relation, no } \\
\text { heterogeneity, no } \\
\text { potential confounding } \\
\text { factors identified, } \\
\text { and eventual } \\
\text { disagreement of } \\
\text { results over time } \\
\text { reasonably explained } \\
\text { [otherwise declassed } \\
\text { as possible]. }\end{array}$ & None. & None. \\
\hline Probable & $\begin{array}{l}\text { Meta-analyses of } \\
\text { prospective cohort } \\
\text { studies with no } \\
\text { heterogeneity, no } \\
\text { potential confounding } \\
\text { factors identified, } \\
\text { and eventual } \\
\text { disagreement of } \\
\text { results over time } \\
\text { reasonably explained } \\
\text { [otherwise declassed } \\
\text { as possible]. }\end{array}$ & None. & None. \\
\hline Possible & $\begin{array}{l}\text { Meta-analysis of } \\
\text { prospective cohort } \\
\text { studies with no } \\
\text { heterogeneity and } \\
\text { lack of information } \\
\text { on potential } \\
\text { confounding factors. }\end{array}$ & $\begin{array}{l}\text { Association } \\
\text { with decreased } \\
\text { risk of adenoma } \\
\text { (colorectal) } \\
\text { and CHD. }\end{array}$ & $\begin{array}{l}\text { Association with } \\
\text { decreased risk of } \\
\text { cancer (colon), } \\
\text { hypertension, } \\
\text { mortality (cancer, } \\
\text { CVD), stroke } \\
\text { (ischemic) }\end{array}$ \\
\hline Limited & $\begin{array}{l}\text { Meta-analysis of } \\
\text { prospective cohort } \\
\text { studies with presence } \\
\text { of significant } \\
\text { heterogeneity ( } I^{2} \\
\text { >50\%) or } \\
\text { identification of } \\
\text { potential confounding } \\
\text { factors (i.e., } \\
\text { different findings in } \\
\text { subgroups). }\end{array}$ & $\begin{array}{l}\text { Association } \\
\text { with decreased } \\
\text { risk of CVD } \\
(\text { any })^{*} \text {. }\end{array}$ & $\begin{array}{l}\text { Association with } \\
\text { decreased risk of } \\
\text { cancer (total)*, CHD } \\
\text { (fatal)*, CVD } \\
\text { (any)*, mortality } \\
\text { (all-cause)*, stroke } \\
\text { (total)* }\end{array}$ \\
\hline $\begin{array}{l}\text { Insuffici } \\
\text { ent }\end{array}$ & $\begin{array}{l}\text { Meta-analysis of } \\
\text { case-control studies, } \\
\text { limited prospective } \\
\text { cohort studies } \\
\text { included in meta- } \\
\text { analyses }(\mathrm{n}<3) \text {, or } \\
\text { evident contrasting } \\
\text { results from meta- } \\
\text { analyses with the }\end{array}$ & None. & $\begin{array}{l}\text { Association with } \\
\text { cancer (acute } \\
\text { myeloid leukemia, } \\
\text { endometrial, } \\
\text { gastric, glioma, } \\
\text { hepatocellular } \\
\text { carcinoma, leukemia, } \\
\text { lymphoma, ovarian, } \\
\text { pancreatic, }\end{array}$ \\
\hline
\end{tabular}




\begin{tabular}{|l|l|l|l|}
\hline & $\begin{array}{l}\text { same level of } \\
\text { evidence. }\end{array}$ & $\begin{array}{l}\text { prostate, stomach, } \\
\text { upper areo- } \\
\text { digestive) }\end{array}$ \\
\hline $\begin{array}{l}\text { No } \\
\text { evidence }\end{array}$ & $\begin{array}{l}\text { Non-significant } \\
\text { results from meta- } \\
\text { analyses of either } \\
\text { prospective or case- } \\
\text { control studies. }\end{array}$ & $\begin{array}{l}\text { No association } \\
\text { with cancer } \\
\text { (colorectal), } \\
\text { stroke, type-2 } \\
\text { diabetes. }\end{array}$ & $\begin{array}{l}\text { No association with } \\
\text { cancer (breast) } \\
\text { myocardial } \\
\text { infarction, type-2 } \\
\text { diabetes. }\end{array}$ \\
\hline $\begin{array}{l}\text { \# all the associations should be biologically plausible; potential } \\
\text { sonfounding factors should be taken into account. } \\
\text { * presence of potential confounding factors }\end{array}$ \\
\hline
\end{tabular}


Articles Identified Through Database Screening $(n=123)$

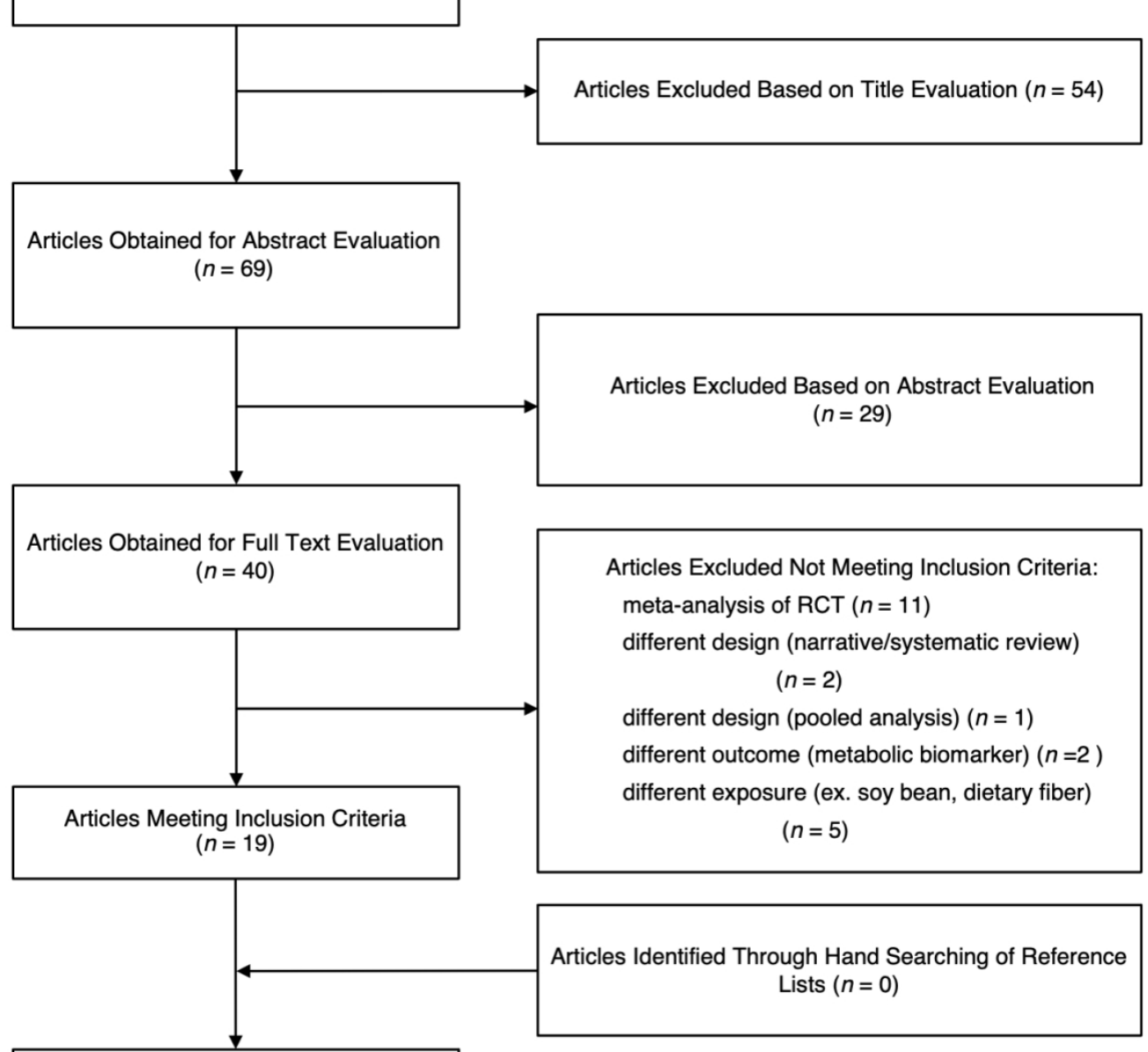

Articles Included in the Umbrella Review $(n=19)$

Fruit $(n=15)$

Legume $(n=6)$ 


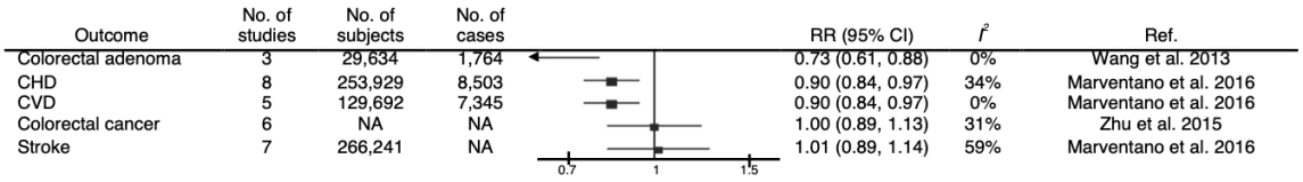

$316 \times 44 \mathrm{~mm}(108 \times 108$ DPI) 


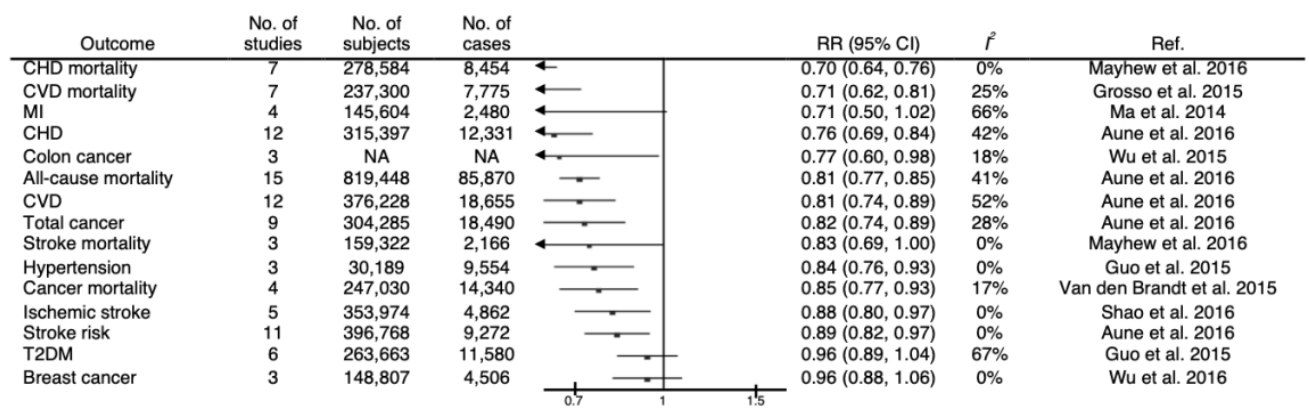

$315 \times 95 \mathrm{~mm}(108 \times 108$ DPI $)$ 
Supplementary Table 1. Summary results from meta-analyses investigating continuous linear exposure to legume consumption and health outcomes.

\begin{tabular}{cccccc}
\hline Outcome & Number of Studies & Exposure (increment) & RR $(95 \% \mathrm{CI})$ & $\mathrm{I} 2$ & Reference \\
\hline CHD & 4 & 4 servings/w $(100 \mathrm{~g} / \mathrm{w})$ & $0.86(0.78,0.94)$ & $0,2 \%$ & Afshin, 2014 \\
Stroke & 6 & 4 servings/w $(100 \mathrm{~g} / \mathrm{w})$ & $0.98(0.84,1.14)$ & $32 \%$ & Afshin, 2014 \\
Diabetes & 2 & 4 servings/w $(100 \mathrm{~g} / \mathrm{w})$ & $0.78(0.50,1.24)$ & $94,6 \%$ & Afshin, 2014 \\
Ischemic stroke & 4 & 4 servings/w $(100 \mathrm{~g} / \mathrm{w})$ & $1.07(0.77,1.50)$ & $60,1 \%$ & Afshin, 2014 \\
Hemorrhagic stroke & 4 & 4 servings/w $(100 \mathrm{~g} / \mathrm{w})$ & $1.23(0.91,1.66)$ & $0 \%$ & Afshin, 2014 \\
\hline
\end{tabular}

Abbreviations: CHD (coronary heart disease). 
Supplementary Table 2. Summary results from meta-analyses investigating continuous linear exposure to nut consumption and health outcomes.

\begin{tabular}{cccccc}
\hline Outcome & Number of Studies & Exposure (increment) & RR $(95 \%$ CI $)$ & I2 & Reference \\
\hline Cancer (total) & 9 & 1 serving $(28 \mathrm{~g}) / \mathrm{d}$ & $0.85(0.76,0.94)$ & $42 \%$ & Aune 2016 \\
Breast cancer & 3 & 1 serving $(28 \mathrm{~g}) / \mathrm{d}$ & $0.96(0.84,1.09)$ & $0 \%$ & Wu 2016 \\
CHD & 12 & 1 serving $(28 \mathrm{~g}) / \mathrm{d}$ & $0.71(0.63,0.80)$ & $47 \%$ & Aune 2016 \\
CVD & 12 & 1 serving $(28 \mathrm{~g}) / \mathrm{d}$ & $0.79(0.70,0.88)$ & $60 \%$ & Aune 2016 \\
CVD mortality & 5 & 1 serving $(28 \mathrm{~g}) / \mathrm{d}$ & $0.61(0.42,0.91)$ & $75 \%$ & Grosso 2015 \\
Hypertension & 3 & 1 serving/w & $0.97(0.83,1.13)$ & $69 \%$ & Guo 2015 \\
All cause mortality & 15 & 1 serving $(28 \mathrm{~g}) / \mathrm{d}$ & $0.78(0.72,0.84)$ & $66 \%$ & Aune 2016 \\
Stroke ischemic & 7 & $12 \mathrm{~g} / \mathrm{d}$ & $0.86(0.79,0.94)$ & $\mathrm{NA}$ & Shao 2016 \\
Stroke & 11 & 1 serving $(28 \mathrm{~g}) / \mathrm{d}$ & $0.93(0.83,1.05)$ & $14 \%$ & Aune 2016 \\
T2DM & 6 & 1 serving/w & $1.00(0.95,1.04)$ & $0 \%$ & Guo 2015
\end{tabular}

Abbreviations: CHD (coronary heart disease), CVD (cardiovascular disease), T2DM (type-2 diabetes mellitus). 


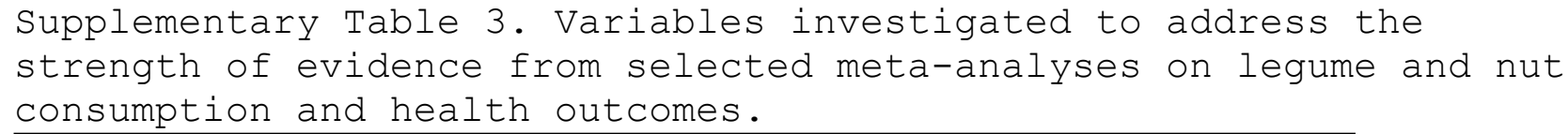

\begin{tabular}{|c|c|c|c|c|c|c|}
\hline Reference & Outcome & 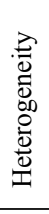 & 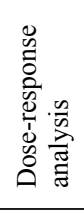 & 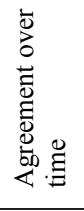 & 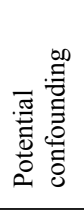 & Reference \\
\hline & Legumes & & & & & \\
\hline Marventano, 2016 & CHD & $\varnothing$ & $\oplus$ & $\oplus$ & $\oplus$ & Marventano, 2016 \\
\hline Marventano, 2016 & Stroke (total) & $\oplus$ & $\oplus$ & $\oplus$ & $\varnothing$ & Marventano, 2016 \\
\hline Marventano, 2016 & CVD (total) & $\varnothing$ & $\oplus$ & $\bigcirc$ & $\varnothing$ & Marventano, 2016 \\
\hline Zhu, 2015 & Cancer (colorectal) & $\varnothing$ & 0 & 0 & $\oplus$ & Zhu, 2015 \\
\hline Wang, 2013 & Adenoma (colorectal) & $\varnothing$ & 0 & 0 & $\bigcirc$ & Wang, 2013 \\
\hline Afshin, 2014 & Stroke (ischemic)* & $\oplus$ & $\oplus$ & $\bigcirc$ & $\bigcirc$ & Afshin, 2014 \\
\hline \multirow[t]{2}{*}{ Afshin, 2014} & Stroke (hemorrhagic)* & $\varnothing$ & $\oplus$ & 0 & $\bigcirc$ & Afshin, 2014 \\
\hline & Nuts & & & & & \\
\hline Aune 2016 & Cancer (any) & $\oplus$ & $\oplus$ & $\varnothing$ & $\oplus$ & Aune 2016 \\
\hline Wu 2016 & Cancer (breast) & $\varnothing$ & $\oplus$ & $\oplus$ & $\bigcirc$ & Wu 2016 \\
\hline Wu 2015 & Cancer (colon) & $\varnothing$ & 0 & 0 & 0 & Wu 2015 \\
\hline Aune 2016 & CHD & $\varnothing$ & $\oplus$ & $\oplus$ & $\oplus$ & Aune 2016 \\
\hline Mayhew 2016 & CHD (fatal) & $\varnothing$ & 0 & $\oplus$ & $\oplus$ & Mayhew 2016 \\
\hline Aune 2016 & CVD & $\varnothing$ & $\oplus$ & $\oplus$ & $\oplus$ & Aune 2016 \\
\hline Grosso 2015 & Mortality (CVD) & $\varnothing$ & $\oplus$ & $\oplus$ & 0 & Grosso 2015 \\
\hline Guo 2015 & Hypertension & $\varnothing$ & $\oplus$ & $\oplus$ & 0 & Guo 2015 \\
\hline Ma 2014 & MI & $\oplus$ & $\bigcirc$ & 0 & 0 & Ma 2014 \\
\hline Aune 2016 & Mortality (all-cause) & $\varnothing$ & $\oplus$ & $\oplus$ & $\oplus$ & Aune 2016 \\
\hline Van den Brandt, & & $\varnothing$ & 0 & $\oplus$ & $\bigcirc$ & \\
\hline 2015 & Mortality (cancer) & & & & & Van den Brandt, 2015 \\
\hline Shao 2016 & Stroke (ischemic) & $\varnothing$ & $\oplus$ & $\varnothing$ & 0 & Shao 2016 \\
\hline Mayhew 2016 & Stroke (mortality) & $\varnothing$ & 0 & $\oplus$ & $\varnothing$ & Mayhew 2016 \\
\hline Aune 2016 & Stroke (total) & $\varnothing$ & $\oplus$ & $\oplus$ & $\oplus$ & Aune 2016 \\
\hline Guo 2015 & T2DM & $\oplus$ & $\oplus$ & $\oplus$ & $\varnothing$ & Guo 2015 \\
\hline
\end{tabular}

*only dose-response meta-analysis.

CVD, cardivoascular disease; CHD, coronary heart disease; MI, myocardial infarction; T2DM, type-2 diabetes.

$\bigcirc$ (denotes lacking information); $\varnothing$ (denotes "no"); $\oplus$ (denotes "yes"). 